\title{
Association between dementia and mortality in the elderly patients undergoing hip fracture surgery: a meta-analysis
}

\author{
Jianzhong Bai ${ }^{1}$, Pei Zhang ${ }^{1}$, Xinyu Liang ${ }^{1}$, Zhipeng $\mathrm{Wu}^{2}$, Jingcheng Wang $^{3 *}$ and Yuan Liang ${ }^{3^{*}}$
}

\begin{abstract}
Objective: This study was designed to verify the association between dementia and mortality in the elderly undergoing hip fracture surgery, and assessed the mortality of patients with dementia after hip fracture surgery.

Material and methods: PubMed, Embase, and Web of Science were searched until April, 2018 without language restrictions. Two reviewers selected related studies, assessed study quality, and extracted data independently. Risk ratios (RRs) with 95\% confidence intervals (Cl) were derived using random-effects model throughout all analyses. The endpoints included 30-day, 6-month, 1-year, and more than 1-year mortality. This meta-analysis was performed following PRISMA statement and carried out by using stata14.0 software.

Results: Dementia significantly increased postoperative mortality of patients suffered from hip fracture in 30-day $[R R=1.57,95 \% \mathrm{Cl}(1.29,1.90), \mathrm{P}<0.00], 6$-month $[\mathrm{RR}=1.97,95 \% \mathrm{Cl}(1.47,2.63), \mathrm{P}<0.00], 1$-year $[\mathrm{RR}=1.77,95 \% \mathrm{Cl}$ $(1.54,2.04), P<0.00]$, and more than 1 -year follow up $[R R=1.60,95 \% \mathrm{Cl}(1.30,1.96), \mathrm{P}<0.00]$ respectively. The mortality of dementia patients after hip fracture surgery in 30-day [ES $=12 \%, 95 \% \mathrm{Cl}(8 \%, 15 \%)]$, 6-month [ES $=32 \%, 95 \% \mathrm{Cl}$ $(17 \%, 48 \%)]$, 1-year [ES $=39 \%, 95 \% \mathrm{Cl}(35 \%, 43 \%)]$, and more than 1-year follow up [ES $=45 \%, 95 \% \mathrm{Cl}(32 \%, 58 \%)]$.

Conclusions: Our meta-analysis demonstrated that the mortality of patients with dementia suffered from hip fracture surgery is $12 \%, 32 \%, 39 \%$, and $45 \%$, and dementia increased $1.57,1.97,1.77$, and 1.60 -fold mortality in patients undergoing hip fracture surgery in 30-day, 6-month, 1-year, and more than 1-year follow up respectively.
\end{abstract}

Keywords: Hip fracture, Mortality, Dementia, Meta-analysis

\section{Introduction}

Hip fractures are being paid more attention due to higher morbidity and mortality. These patients usually have poor body compensatory capacity and comorbidities, such as dementia. Dementia is a syndrome characterized by persistent impairment in cognitive function or behavioral abnormalities. Due to the progress of aging society, dementia prevalence increases exponentially with age, it is estimated that the number of patients with dementia may reach 65.7 million in 2030 and 115.4 million in 2050 [1].

Dementia is not as fatal as deep vein thrombosis or pulmonary embolism in the short term, so it did not cause clinicians to pay enough attention, and it is

\footnotetext{
* Correspondence: wangjcyangzhou@163.com; 464156241@qq.com ${ }^{3}$ Clinical Medical College of Yangzhou University, Yangzhou 225001, China Full list of author information is available at the end of the article
}

unclear that the mortality of patients with dementia suffered from hip fracture surgery. Therefore, we performed a meta-analysis based on plenty of previous achievements in current research, to identify the effects of dementia on postoperative mortality of hip fracture, and the incidence of death in patients with dementia undergoing hip fracture surgery in 30 days, 6 months, 1 year, and more than 1 year follow up, and provided more convincing evidences for clinicians.

\section{Materials and methods}

We carried out this meta-analysis according to the Preferred Reporting Items for Systematic Reviews and Meta-Analysis (PRISMA) statement [2] and Cochrane Collaboration guidelines strictly [3]. 


\section{Search strategy}

We searched PubMed, Embase, and Web of Science until April, 2018, without language restrictions. In addition, the references of the included studies were manual searched to identify any additional articles. The following keywords were adopted in the database search: "hip fracture," "mortality," and "dementia." The Boolean operators were used to combine them.

\section{Study selection and eligibility criteria}

The inclusion criteria are as follows: (1) studies examined the relationship between dementia and mortality among elderly patients undergoing hip fracture surgery; (2) the sample size was more than 200; (3) study designs were cohort study; (4) the mean age is greater than 60 years. The exclusion criteria are as follows: (1) other types of fractures included; (2) studies provided insufficient data; (3) case report, review, commentary, and study just included an abstract; (4) dementia with other psychiatric disorders.

\section{Data extraction}

Two reviewers (JZ B and P Z) independently extracted the following information from each study: first author, year of publication, country, study design, sample size, mean age, diagnostic criteria for dementia, and duration of follow-up (in-hospital, perioperative setting, 30-day, 6-month, 1-year and more than 1-year). Any discrepancies were resolved following discussion. All extracted data were entered into a predefined standardized Excel (Microsoft Corporation, USA) file carefully.

\section{Quality assessment}

We evaluated the quality of studies by Newcastle-Ottawa Scale (NOS), which is a risk of bias assessment tool for observational studies [4]. This scale contains a number of answers per question ranging from two to five. Highquality responses earn a star, totaling up to nine stars. We set scores of 0-3, 4-6, and 7-9 for low, moderate, and high quality of studies, respectively [5].

\section{Statistical analysis}

Statistical analyses were performed by using STATA 14.0 (StataCorp LP). The association between dementia and mortality was described as risk ratios (RR) with 95\% confidence intervals $(\mathrm{CI})$ by using random models. $P \leq$ 0.05 was regarded as statistically significant. Statistical heterogeneity was assessed by the Cochran $\mathrm{Q}$ test and quantified by the $I^{2}$ statistic [6], and an $I^{2}$ value greater than $50 \%$ indicates significant heterogeneity. When significant heterogeneity existed, heterogeneity analysis would be conducted to make a further explanation. We divided the follow-up time into four timepoints: 30-day, 6-month, 1-year, and more than 1-year follow-up. We classified the in-hospital and perioperative mortality as 30-day mortality.

\section{Results \\ Study characteristics and quality assessment}

Two reviewers (JZ B and P Z) independently undertook the searches. Endnote X8 (version 18.0.0.10063) was used to remove duplicate studies. Additionally, we deleted irrelevant articles through the full text. Finally, 18 articles were included. The study selection process was shown in Fig. 1, and the main characteristics of the included trials were summarized in Table 1 . Fourteen of 18 were prospective cohort studies [7-20], and four were retrospective cohort studies [21-24]. These studies enrolling 295,285 subjects were published between 2000 and 2018, with a sample size ranging from 272 to 134,144 . The average scores of the quality assessment were 7.3 (range, 7-9). Details of the quality assessment were available in Table 2.

\section{Thirty-day mortality}

Seven studies $[7,13,15,18,19,21,24]$ provided available data, and the pooled results suggested that dementia significantly increased the mortality of patients undergoing hip fracture surgery $[R R=1.57,95 \% \mathrm{CI}$ $(1.29,1.90), P<0.001, I^{2}=23.4 \%$; Fig. 2], and the mortality of patients with dementia suffered from hip fracture surgery [ES $=12 \%, 95 \% \mathrm{CI}(8 \%, 15 \%), I^{2}=77.5 \%$; Fig. 3].

\section{Six-month mortality}

Only two studies $[8,11]$ provided available data in 6-month follow-up. The pooled outcomes suggested that dementia significantly increases the mortality of patients after hip fracture surgery $[R R=1.97,95 \% \mathrm{CI}(1.47,2.63)$, $P>0.001, I^{2}=41.8 \%$; Fig. 2], and the mortality of the dementia patients suffered from hip fracture surgery [ES = $32 \%, 95 \%$ CI (17\%, 48\%), $I^{2}=91.8 \%$; Fig. 3$]$.

\section{One-year mortality}

Seven studies $[8,10,13,14,17,22,23]$ provided available data, and the pooled results suggested that dementia significantly increases the mortality of patients undergoing hip fracture surgery in 1-year follow up [RR $=1.77,95 \%$ CI $(1.54,2.04), P<0.001, I^{2}=91.7 \%$; Fig. 2], and the mortality of the dementia patients suffered from hip fracture surgery [ES $=39 \%, 95 \%$ CI $(35 \%, 43 \%), I^{2}=$ 89.8\%; Fig. 3].

\section{More than one-year mortality}

Five studies $[8,9,12,16,20]$ reported more than 1-year mortality. The pooled outcomes suggested that dementia significantly increases the mortality of patients undergoing hip fracture surgery $[R R=1.60,95 \%$ CI $(1.30,1.96)$, $P<0.001, I^{2}=87 \%$; Fig. 2], and the mortality of the 


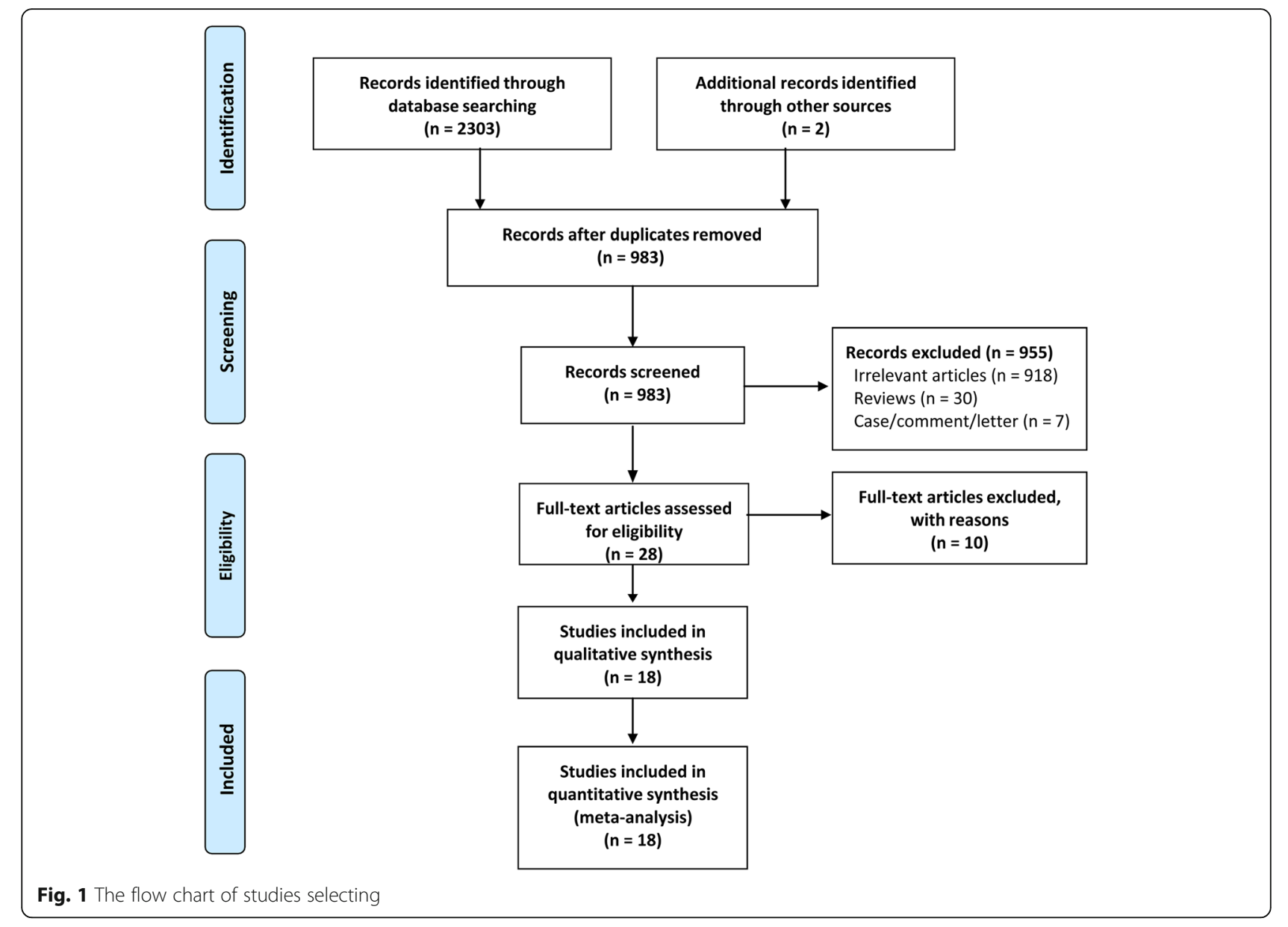

dementia patients suffered from hip fracture surgery [ES $=45 \%, 95 \%$ CI (32\%, 58\%), $I^{2}=97.3 \%$; Fig. 3].

\section{Discussion}

\section{Main findings}

Our meta-analysis demonstrated that the mortality of patients with dementia suffered from hip fracture surgery is $12 \%, 32 \%, 39 \%$, and $45 \%$, and dementia increased $1.57,1.97,1.77$, and 1.60-fold mortality in patients undergoing hip fracture surgery in 30-day, 6-month, 1-year, and more than 1-year follow-up. A previous meta-analysis included 75 studies, and involving 64,316 patients [25], the pooled outcomes demonstrated that the overall inpatient or 1 month mortality was $13.3 \%, 3$ to 6 months was $15.8 \%, 1$ year $24.5 \%$, and 2 years $34.5 \%$ in generally patients, which mortality was significantly lower than patients with dementia who underwent hip fracture surgery.

\section{Comparison with other studies}

To the best of our knowledge, there are three meta-analyses that described risk factors for postoperative mortality after hip fracture surgery [25-27], which dementia is one of these risk factors. However, these meta-analyses included fewer literatures for the indicator of dementia, and inconsistent follow-up time made conclusions less convincing. Therefore, we performed an update meta-analysis to evaluate the effects of dementia on postoperative mortality of patients undergoing hip fracture surgery and the incidence of death in patients with dementia undergoing hip fracture surgery in 30 days, 6 months, 1 year, and more than 1 year follow-up.

\section{Implications for clinical practice}

Dementia has not received enough attention compared with deep vein thrombosis and pulmonary embolism in patients with hip fracture. However, our pooled results demonstrated that more than one third of people with dementia will die after hip fracture surgery in a 1-year follow-up and about one in two in more than 1-year follow-up. Patients with dementia usually have less activity and poor self-care ability, which increased postoperative complications, such as surgical site infection, urinary tract infection, and respiratory complications [28]. Therefore, orthopedists should attach great importance to this age-related disease, instead of just focusing 


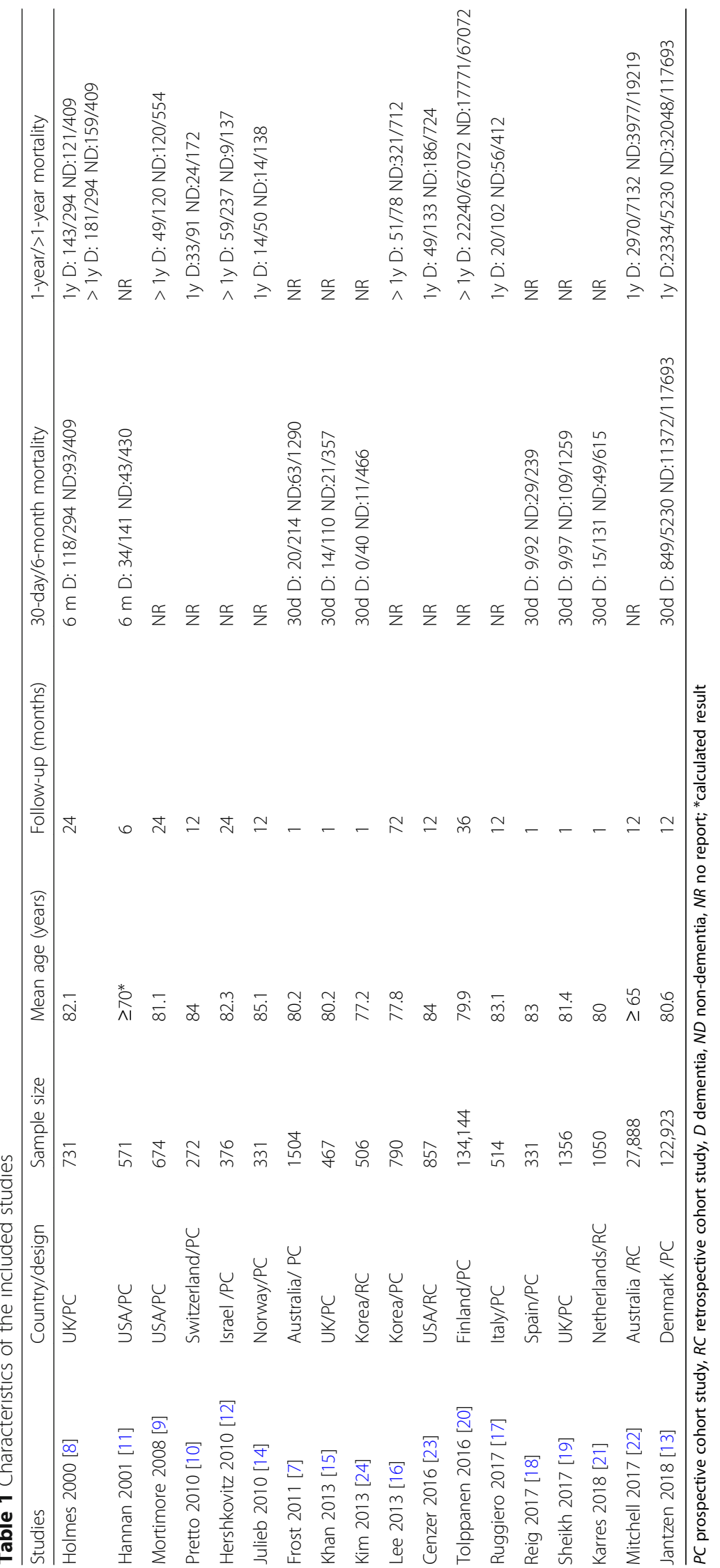


Table 2 Methodological quality assessment of included studies by Newcastle-Ottawa scales

\begin{tabular}{|c|c|c|c|c|c|c|c|c|c|}
\hline \multirow{2}{*}{ Study } & \multicolumn{4}{|l|}{ Selection } & \multirow[t]{2}{*}{ Comparability } & \multicolumn{4}{|l|}{ Outcome } \\
\hline & $\begin{array}{l}\text { Exposed } \\
\text { Cohort }\end{array}$ & $\begin{array}{l}\text { Nonexposed } \\
\text { Cohort }\end{array}$ & $\begin{array}{l}\text { Ascertainment } \\
\text { of exposure }\end{array}$ & $\begin{array}{l}\text { Outcome } \\
\text { of interest }\end{array}$ & & $\begin{array}{l}\text { Assessment } \\
\text { of outcome }\end{array}$ & $\begin{array}{l}\text { Length of } \\
\text { follow-up }\end{array}$ & $\begin{array}{l}\text { Adequacy } \\
\text { of follow-up }\end{array}$ & Total score \\
\hline Holmes et al. & * & * & * & * & * & * & * & * & 8 \\
\hline Hannan et al. & * & * & * & $*$ & $*$ & $*$ & - & $*$ & 7 \\
\hline Mortimore et al. & * & * & * & * & * & * & * & * & 8 \\
\hline Pretto et al. & * & * & $*$ & $*$ & $*$ & * & - & $*$ & 7 \\
\hline Julieb et al. & $*$ & $*$ & * & $*$ & $*$ & * & - & $*$ & 7 \\
\hline Hershkovitz et al & * & * & * & * & $*$ & * & * & * & 8 \\
\hline Frost et al. & * & * & $*$ & $*$ & $*$ & * & - & $*$ & 7 \\
\hline Lee et al. & * & * & * & * & * & * & * & * & 8 \\
\hline Khan et al. & * & * & $*$ & $*$ & $*$ & * & - & * & 7 \\
\hline Kim et al. & * & * & * & $*$ & * & $*$ & - & * & 7 \\
\hline Cenzer et al. & * & * & * & $*$ & * & * & - & * & 7 \\
\hline Tolppanen et al. & * & * & * & * & $* *$ & * & * & $*$ & 9 \\
\hline Ruggiero et al. & $*$ & * & * & * & * & * & - & * & 7 \\
\hline Reig et al. & * & * & * & $*$ & $*$ & * & - & * & 7 \\
\hline Sheikh et al. & $*$ & * & * & * & * & * & - & * & 7 \\
\hline Karres et al. & * & * & * & * & $*$ & * & - & $*$ & 7 \\
\hline Mitchell et al. & * & * & $*$ & $*$ & $*$ & * & - & * & 7 \\
\hline Jantzen et al. & * & * & $*$ & * & * & * & - & * & 7 \\
\hline
\end{tabular}

Single asterisk indicates 1 score; double asterisk indicates 2 scores, and dash indicates 0 scores

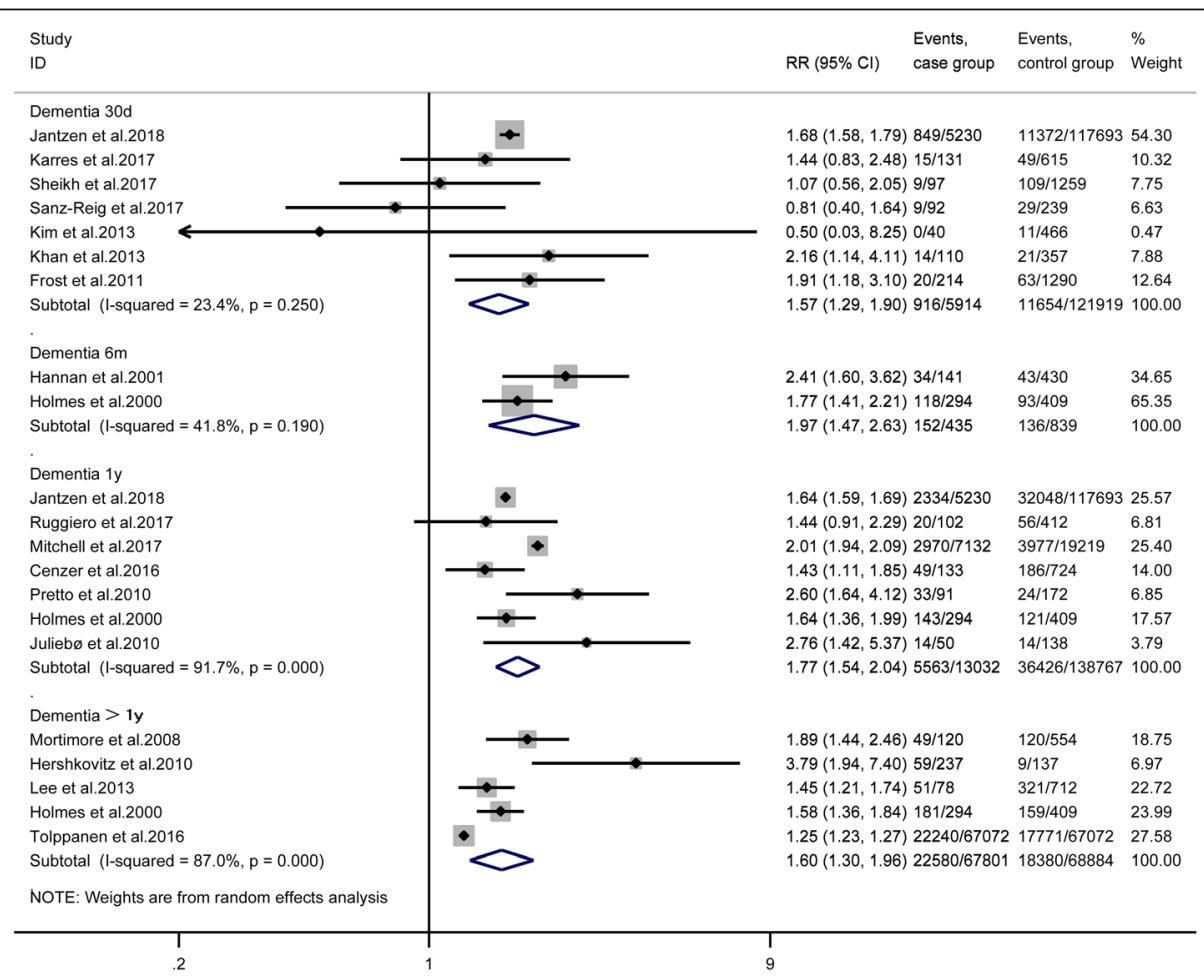

Fig. 2 The effect of dementia on the mortality of patients after hip fracture surgery 


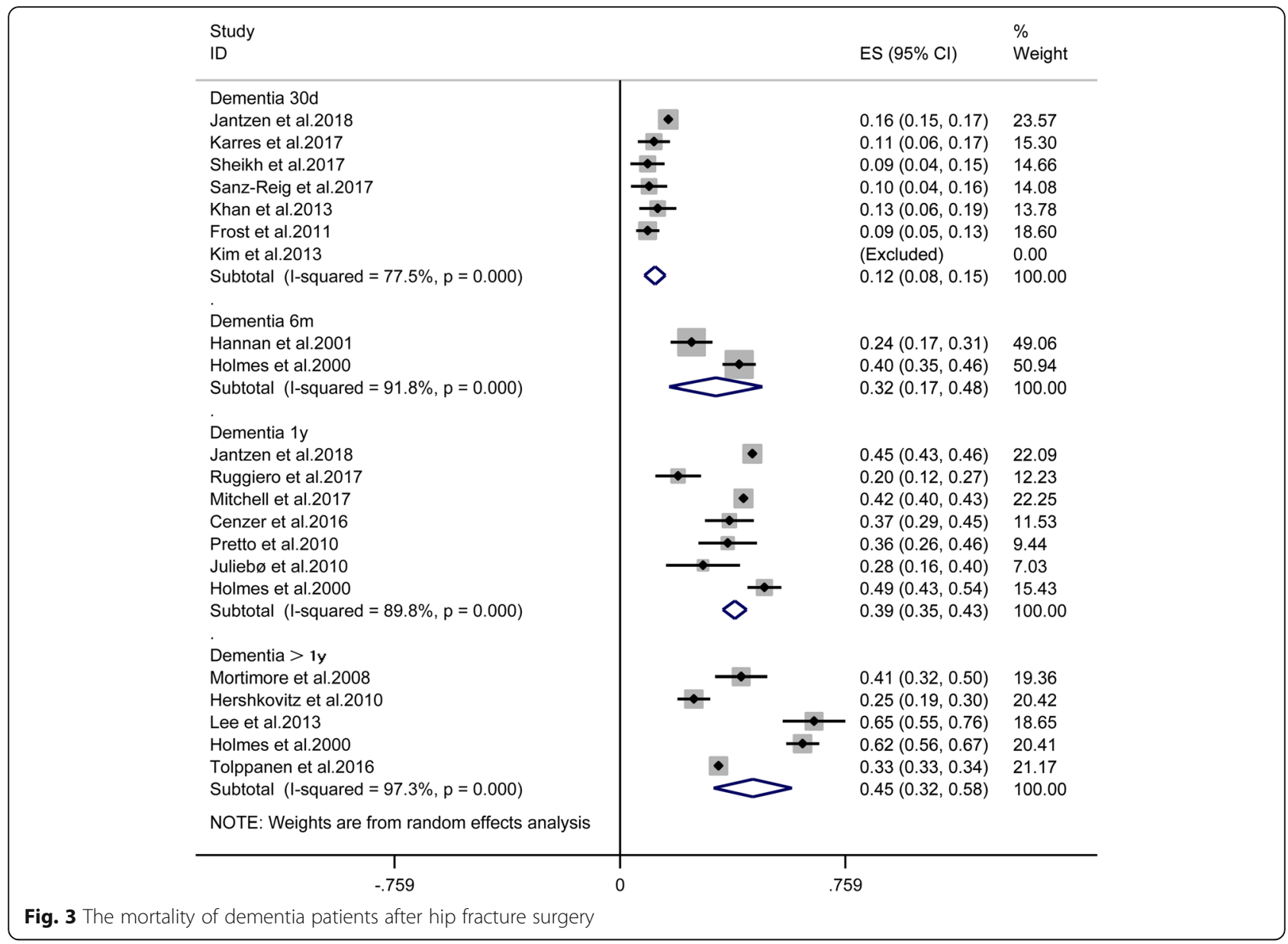

on hip fracture problems. Besides, they should fully assess whether the dementia patients are suitable for surgical treatment after suffering from a hip fracture. Can surgical treatment improve the quality of life and prolong life span of patients, especially for patients with severe dementia? For patients with dementia who underwent hip fracture surgery, we should establish a multidisciplinary model of diagnosis and treatment to improve the postoperative outcomes [29]. Besides, nursing cares are necessary to prevent the adverse outcomes of dementia postoperatively [30], such as aspiration, pressure sore, deep vein thrombosis, and pneumonia. Further, rehabilitate exercises are needed to restore function as much as possible after discharge.

\section{Call for future studies}

Our results show that patients with dementia have very high mortality rates after undergoing hip fracture surgery. Mortality will be higher for patients with severe dementia. It is unclear whether surgical treatment could improve quality of life and prolong life-span of patients with severe dementia. Until recently, there is no relevant meta-analysis or clinical guidelines to elaborate on this issue. We recommend that future studies should focus on which one is better for the treatment of patients with severe dementia who suffered from hip fracture, surgery, or conservative treatment. Besides, clinical decision makers should formulate relevant clinical guidelines to guide clinicians in the treatment of patients with dementia suffered from hip fracture.

\section{Heterogeneity analysis}

The pooled results indicated that significant heterogeneity was found in some indicators. For the prevalence of death of patients with dementia after hip fracture surgery, (1) we conducted a sensitivity analysis through the deletion of Jantzen et al's study [13], and the heterogeneity was reduced from 77.5 to $0.0 \%$ in 30 -day mortality; (2) we excluded each study of the outcomes one at a time in 1-year mortality, but the heterogeneity was still very high. Unequal levels of regional medical care and significant sample size difference in the included studies may be the major sources of heterogeneity. For the effect of dementia on postoperative mortality, there was significant heterogeneity in 1-year mortality. The heterogeneity was reduced from 91.7 to $33.8 \%$ after the removal of Mitchell 
et al's study [22]. Only two studies were included in 6-month mortality, which may be the main source of heterogeneity. In terms of more than 1-year mortality, the inconsistency of follow-up time and obvious sample size differences, which may be major sources of higher heterogeneity.

\section{Strengths and limitations of this meta-analysis}

The major strengths of this study were the following: (1) our study was restricted to the elderly dementia patients undergoing hip fracture surgery, which were higher homogeneous and selective; (2) we designed our meta-analysis into four timepoints: 30-day, 6-month, 1-year, and more than 1-year follow up, and follow-up time is consistent; (3) we calculated the mortality of patients with dementia suffered from hip fracture surgery.

Limitations of this meta-analysis must be considered. First, although the patients we included in the study were elderly patients, it is difficult to make the confounding variables among the studies exactly the same. Second, we did not classify dementia into mild, moderate, and severe dementia because no related data were available in the original studies. Third, there was a great difference in the sample size of the included studies, which may affect the accuracy of our results to some extent. Fourth, significant heterogeneity was found in some outcomes. Last, although we conducted a comprehensive search of literature, it was hard to rule out the existence of publication bias.

\section{Conclusions}

Our meta-analysis demonstrated that the mortality of people with dementia suffered from hip fracture surgery is $12 \%, 32 \%, 39 \%$, and $45 \%$, and dementia increased 1.57 -, $1.97-, 1.77-$, and 1.60-fold mortality in patients undergoing hip fracture surgery in 30-day, 6-month, 1-year, and more than 1-year follow-up. Future large-volume, well-designed studies, and the outcomes of multivariable analysis with extensive follow-up are awaited to confirm and update the findings of our analysis.

\section{Abbreviations}

Cl: Confidence interval; D: Dementia; ND: Non-dementia; NOS: NewcastleOttawa Scale; NR: No report; PC: Prospective cohort study; RC: Retrospective cohort study; RR: Risk ratio

\section{Acknowledgements}

We thank the authors of the included studies for their helping.

\section{Funding}

This study was supported by the project foundation of Northern Jiangsu People's Hospital: (yzucms201623), (fcjs201715); National Natural Science Foundation of China: (81772332)

Availability of data and materials

All data are fully available without restriction.

\section{Authors' contributions}

$J C W, Y L$, and JZB conceived of the design of the study. JZB and PZ participated in the literature search, study selection, data extraction, and quality assessment. XYL and ZPW performed the statistical analysis. JZB finished the manuscript. All authors read and approved the final manuscript.

\section{Authors' information}

The author information can be found in the title page.

Ethics approval and consent to participate

All analyses were based on previously published studies; thus, no ethical approval and patient consent are required.

\section{Consent for publication}

Not applicable.

\section{Competing interests}

The authors declare that they have no competing interests.

\section{Publisher's Note}

Springer Nature remains neutral with regard to jurisdictional claims in published maps and institutional affiliations.

\section{Author details}

${ }^{1}$ Dalian Medical University, Dalian 116044, Liaoning, China. ${ }^{2}$ The second XiangYa hospital, Central South University, Changsha 410011, China. ${ }^{3}$ Clinical Medical College of Yangzhou University, Yangzhou 225001, China.

Received: 14 May 2018 Accepted: 26 October 2018

Published online: 23 November 2018

\section{References}

1. Prince M, Bryce R, Albanese E, Wimo A, Ribeiro W, Ferri CP. The global prevalence of dementia: a systematic review and metaanalysis. Alzheimers Dement. 2013;9(1):63-75.e62.

2. Moher D, Liberati A, Tetzlaff J, Altman DG. Preferred reporting items for systematic reviews and meta-analyses: the PRISMA statement. Int I Surg. 2010;8(5):336-41.

3. Higgins J, Green S: Cochrane handbook for systematic reviews of interventions version 5.1.0 [updated March 2011]. Cochrane Collab 2011. Available at: www.handbook.cochrane.org. Accessed 24 Apr 2016.

4. Stang A. Critical evaluation of the Newcastle-Ottawa scale for the assessment of the quality of nonrandomized studies in meta-analyses. Eur J Epidemiol. 2010;25(9):603-5.

5. Gu WJ, Wu XD, Zhou Q, et al. Relationship between annualized case volume and mortality in sepsis: a dose-response meta-analysis. Anesthesiology. 2016:125(1):168-79.

6. Higgins JP, Thompson SG. Quantifying heterogeneity in a meta-analysis. Stat Med. 2002;21(11):1539-58.

7. Frost SA, Nguyen ND, Black DA, Eisman JA, Nguyen TV. Risk factors for inhospital post-hip fracture mortality. Bone. 2011:49(3):553-8.

8. Holmes J, House A. Psychiatric illness predicts poor outcome after surgery for hip fracture: a prospective cohort study. Psychol Med. 2000;30(4):921-9.

9. Mortimore E, Haselow D, Dolan M, et al. Amount of social contact and hip fracture mortality. J Am Geriatr Soc. 2008;56(6):1069-74.

10. Pretto M, Spirig R, Kaelin R, Muri-John V, Kressig RW, Suhm N. Outcomes of elderly hip fracture patients in the Swiss healthcare system: a survey prior to the implementation of DRGs and prior to the implementation ofa geriatric fracture Centre. Swiss Med Wkly. 2010;140:w13086.

11. Hannan EL, Magaziner J, Wang JJ, et al. Mortality and locomotion 6 months after hospitalization for hip fracture - risk factors and risk-adjusted hospital outcomes. JAMA. 2001;285(21):2736-42.

12. Hershkovitz A, Polatov I, Beloosesky Y, Brill S. Factors affecting mortality of frail hip-fractured elderly patients. Arch Gerontol Geriatr. 2010;51(2):113-6.

13. Jantzen C, Madsen CM, Lauritzen JB, Jorgensen HL. Temporal trends in hip fracture incidence, mortality, and morbidity in Denmark from 1999 to 2012. Acta Orthop. 2018:1-7. https://doi.org/10.1080/17453674.2018.1428436.

14. Juliebø V, Krogseth M, Skovlund E, Engedal K, Ranhoff AH, Wyller TB. Delirium is not associated with mortality in elderly hip fracture patients. Dement Geriatr Cogn Disord. 2010;30(2):112-20. 
15. Khan MA, Hossain FS, Ahmed I, Muthukumar N, Mohsen A. Predictors of early mortality after hip fracture surgery. Int Orthop. 2013;37(11):2119-24.

16. Lee SR, Ha YC, Kang H, Park YG, Nam KW, Kim SR. Morbidity and mortality in Jeju residents over 50-years of age with hip fracture with mean 6-year follow-up: a prospective cohort study. J Korean Med Sci. 2013;28(7):1089-94.

17. Ruggiero C, Bonamassa L, Pelini L, et al. Early post-surgical cognitive dysfunction is a risk factor for mortality among hip fracture hospitalized older persons. Osteoporos Int. 2017;28(2):667-75.

18. Sanz-Reig J, Salvador Marin J, Perez Alba JM, Ferrandez Martinez J, Orozco Beltran D, Martinez Lopez JF. Risk factors for in-hospital mortality following hip fracture. Rev Esp Cir Ortop Traumatol. 2017:61(4):209-15.

19. Sheikh HQ, Hossain FS, Aqil A, Akinbamijo B, Mushtaq V, Kapoor H. A comprehensive analysis of the causes and predictors of 30-day mortality following hip fracture surgery. Clin Orthop Surg. 2017;9(1):10-8.

20. Tolppanen AM, Taipale H, Tanskanen A, Tiihonen J, Hartikainen S. Comparison of predictors of hip fracture and mortality after hip fracture in community-dwellers with and without Alzheimer's disease - exposurematched cohort study. BMC Geriatr. 2016;16(1):204.

21. Karres J, Kieviet N, Eerenberg JP, Vrouenraets BC. Predicting early mortality after hip fracture surgery: the hip fracture estimator of mortality Amsterdam. J Orthop Trauma. 2018;32(1):27-33.

22. Mitchell R, Harvey L, Brodaty H, Draper B, Close J. One-year mortality after hip fracture in older individuals: the effects of delirium and dementia. Arch Gerontol Geriatr. 2017;72:135-41.

23. Cenzer IS, Tang V, Boscardin WJ, et al. One-year mortality after hip fracture: development and validation of a prognostic index. J Am Geriatr Soc. 2016; 64(9):1863-8.

24. Kim SD, Park SJ, Lee DH, Jee DL. Risk factors of morbidity and mortality following hip fracture surgery. Korean J Anesthesiol. 2013;64(6):505-10.

25. Hu F, Jiang C, Shen J, Tang P, Wang Y. Preoperative predictors for mortality following hip fracture surgery: a systematic review and meta-analysis. Injury. 2012;43(6):676-85.

26. Norring-Agerskov D, Laulund AS, Lauritzen JB, et al. Metaanalysis of risk factors for mortality in patients with hip fracture. Dan Med J. 2013;60(8): A4675.

27. Smith T, Pelpola K, Ball M, Ong A, Myint PK. Pre-operative indicators for mortality following hip fracture surgery: a systematic review and metaanalysis. Age Ageing. 2014;43(4):464-71.

28. Tsuda Y, Yasunaga H, Horiguchi H, Ogawa S, Kawano H, Tanaka S. Association between dementia and postoperative complications after hip fracture surgery in the elderly: analysis of 87,654 patients using a national administrative database. Arch Orthop Trauma Surg. 2015;135(11):1511-7.

29. Stenvall M, Berggren M, Lundstrom M, Gustafson Y, Olofsson B. A multidisciplinary intervention program improved the outcome after hip fracture for people with dementia--subgroup analyses of a randomized controlled trial. Arch Gerontol Geriatr. 2012:54(3):e284-9.

30. Kim SK, Park M. Effectiveness of person-centered care on people with dementia: a systematic review and meta-analysis. Clin Interv Aging. 2017;12: $381-97$

Ready to submit your research? Choose BMC and benefit from:

- fast, convenient online submission

- thorough peer review by experienced researchers in your field

- rapid publication on acceptance

- support for research data, including large and complex data types

- gold Open Access which fosters wider collaboration and increased citations

- maximum visibility for your research: over $100 \mathrm{M}$ website views per year

At $\mathrm{BMC}$, research is always in progress.

Learn more biomedcentral.com/submissions 